\title{
Production of Biodiesel with Seed Soybean and Supercritical Ethanol
}

\author{
Gabriel Cassemiro Mariano1 ${ }^{*}$, Toni Jefferson Lopes², Rafael Dias', \\ Marintho Bastos Quadri' ${ }^{1}$ Ariovaldo Bolzan1 \\ ${ }^{1}$ Laboratory of Process Control (LCP), Chemical Engineering, Federal University of Santa Catarina (UFSC), \\ Florianópolis, Brasil \\ ${ }^{2}$ Federal University of Rio Grande (FURG), Campus Santo Antônio da Patrulha (SAP), Rio Grande do Sul, Brasil \\ Email: gabrielmarianoc@gmail.com
}

Received 7 March 2014; revised 11 May 2014; accepted 26 May 2014

Copyright (C) 2014 by authors and Scientific Research Publishing Inc.

This work is licensed under the Creative Commons Attribution International License (CC BY). http://creativecommons.org/licenses/by/4.0/

c) (i) Open Access

\section{Abstract}

This paper presents a study of biodiesel production by a non-catalytical process. The innovation in this study is the use of novel materials for production: seed soybean (Glycine Max) "in natura" and ethanol in a supercritical state. To conduct the experiments, a bench reactor with a capacity of 150 $\mathrm{mL}$, resistant to pressure of up to 300 bar and temperature of $350^{\circ} \mathrm{C}$ was developed. The fractional factorial experimental design $\left(2_{\mathrm{IV}}^{4-1}\right.$ ) was used to evaluate the temperature, seed granulometry, molar ratio ethanol/oil and water percent of the mixture. The best yield observed was that of $\mathbf{9 4 . 0 7 \% , 1 0 ~ m i n u t e s ~ a f t e r ~ t h e ~ r e a c t o r ~ e n t e r e d ~ a ~ s u p e r c r i t i c a l ~ c o n d i t i o n . ~ S i g n i f i c a n t ~ e f f e c t s ~ o n ~ s e e d ~}$ granulometry, molar ratio ethanol, oil and temperature were verified. From the proposed process, biodiesel and toasted soybean seed were obtained. To purify the biodiesel sample it was necessary to use ultra-centrifugation to separate seed particles, and rotoevaporation to separate the fatty acid ethyl ester and unreacted ethanol. The chemical analyses were conducted directly by gas chromatography. The yield was calculated in accordance with concentrations obtained in the chromatographic analysis and seed mass of the experiment. Also checked was the presence of palmitate esters, stearate, oleate, linoleate and linolenate. By analyzing the ester composition it was possible to assess whether a good quality biodiesel was available. The roasted soybean seeds obtained after the reaction showed a calorific potential of $2203.17 \mathrm{kcal} / \mathrm{kg}$ and also were used as fuel.

\section{Keywords}

Supercritical, Biodiesel, Non-Catalytic Transesterification, Ethyl Ester, Soybean Seed

${ }^{*}$ Corresponding author. 


\section{Introduction}

Several technologies have been studied with a view to optimizing the reaction process of transformation of triglyceride esters in biodiesel. The non-catalytic transesterification with an alcohol in supercritical conditions has been highlighted as an alternative method for the production of biodiesel [1]. Some advantages of a supercritical process of transesterification using alcohol and oil are quick reaction time, and the removal of need for standardization of raw material.

Although it is necessary to have a detailed procedure to convert vegetable oil to esters of biodiesel, it is possible to confirm that the process of transesterification of vegetable oils is mostly viable [2]. Chemically, the transesterification of oils means to take the complex fatty acid triglycerides and transform them into three molecules of fatty acid esters (biodiesel) and one glycerol molecule. The mechanism for the transesterification of vegetable oil in supercritical conditions depends on pressure and temperature. The hydrogen bonding is weaker than other bondings of triglyceride, allowing the alcohol to become a free radical. The proposition is that due to high pressure the alcohol molecule attacks the carbonyl oxygen, and the triglyceride transesterification reaction is completed by transferring methoxide or ethoxide, forming ester and diglyceride in a similar reaction to that by which the diglyceride and monoglyceride were transesterificated [3].

Methanolysis is a more viable technology than ethanolysis [4] [5]; however methanol is toxic and the fatty acid methyl ester is not a totally renewable fuel. Ethanol surpasses methanol because it is derived from agricultural sources and, being a renewable source, is less environmentally damaging —although more expensive and less reactive. When used as a transesterified agent, ethanol has better solvency. Studies of supercritical trancesterification of soybean oil and ethanol in a supercritical state were verified using a continuous reactor with yields of around $80 \%$ [6] [7].

From an experiment with oil and methanol, it was identified that temperature is the variable that most affects the speed and performance of the transesterification reaction [8]. This experiment was conducted by way of a non-catalytic transesterification of vegetable oil using supercritical ethanol in a continuous tubular reactor. The experiments were conducted at 200 bar at a temperature of $350^{\circ} \mathrm{C}$. Also evaluated were the molar ratios of oil: ethanol (R) 1:10, 1:20,1:40, 1:60 and 1:100, and from this analysis it was evident that increasing the alcohol content by a particular molar ratio does not affect the balance of the reaction [6].

The solubility of soybean oil in methanol or ethanol is strongly dependent upon temperature and pressure. Temperature can be correlated with the pressure increase and the increase in the yield of the transesterification reaction. Through controlled pressure it is possible to correlate the temperature increase with increased reaction yield. This is due to interaction between oil and alcohol, which is favored in improving the dynamics of trancesterification [9].

The production of biodiesel from soybean seed is an innovative process which requires less raw material preparation. The process was developed using the raw materials of soybean seed "in natura", and ethanol; a catalyst was not necessary. The objective of this study is to evaluate the process of non-catalytic biodiesel production from soybean seed (Glycine max).

\section{Material and Methods}

The bench scale reactor was developed to support a pressure of 300 bar at a temperature of $350^{\circ} \mathrm{C}$. The equipment was modeled primarily using solid modeling software, and was designed piece by piece. The reactor has an inert structure in which introduced reagents only come into contact with the stainless steel walls.

To produce biodiesel, soybean seeds "in natura” were used along with pure ethanol. To prepare for the experiment the seed was soaked in ethanol, the objective being to expel the oxygen from the pores of the seed and to optimize the contact area between the ethanol and the surface of the soybean seed. In the next step the seed was placed inside the cartridge. The desired molar ratio was achieved by addition of ethanol into the reactor. It was considered that $20 \%$ of a soybean's weight is constituted of oil.

For evaluation of levels and factors with greater significance and the best yield, a fractional factorial experimental design model with a triplicate central point was employed. Table 1 shows the factors and levels evaluated.

The chemical analyses were made directly by capillary gas chromatography, using a GC Shimadzu, equipped with FID and a capillary column SGE BPX70 $(25 \mathrm{~m} \times 0.5 \mathrm{~mm} \times 0.25 \mu \mathrm{m})$. Also utilized were the guidelines of ASTM D6584/ISSO EN14105. The samples for chemical analysis were prepared with hexane solvent, stearic 
Table 1. Factors and experimental levels evaluated.

\begin{tabular}{cccc}
\hline Factors/Levels & -1 & 0 & +1 \\
\hline Seed granulometry & Entire seed & $\begin{array}{c}\text { Broken seed } \\
\text { (2 parts) }\end{array}$ & $\begin{array}{c}\text { Irregular broken seed } \\
\text { (passed through mesh No. 5) }\end{array}$ \\
Molar ratio (ethanol:oil) & $10: 1$ & $20: 1$ & $30: 1$ \\
Temperature & $245.0^{\circ} \mathrm{C}$ & $255.0^{\circ} \mathrm{C}$ & $265.0^{\circ} \mathrm{C}$ \\
Water percent of mixture & $17 \%$ & $11 \%$ & $5 \%$ \\
\hline
\end{tabular}

acid standard solution and biodiesel. The concentrations of the esters are represented in $\mathrm{mg} / \mathrm{L}$ and processed in percent yield w/w. Was considered the mass of oil in the seed obtained by Soxhlet extraction, $20 \%$ of oil inside seed.

The concentration of biodiesel is calculated based on the volume of the sample dilution. Thus, according to the peak area of the standard solution, the correlation with the different peak area ester is made, and it is possible to identify the ester concentration. The concentrations were calculated according to Equation (1).

$$
C_{e ́ s t}=\frac{A_{a m}}{A_{p i}} \times \frac{C_{p i}}{\alpha_{e s t}} \times D_{a m}
$$

where $C_{e ́ s t}$ is the ester concentration; $A_{a m}$ is the peak area ester indicated by the chromatogram; $A_{p i}$ is the peak area of standard solution; $C_{p i}$ is the standard solution concentration; $\alpha_{e s t}$ is the correlation factor to ester and internal standard; and $D_{a m}$ is the sample dilution.

The analysis of soybean seed residue involved an evaluation to identify the potential heat of the seed residue. A thermogravimetric analysis (TGA-DTA) was made under the conditions of a nitrogen atmosphere, a seed mass of $10.0 \mathrm{mg}$ and heating up by $10^{\circ} \mathrm{C}$ per minute to $900^{\circ} \mathrm{C}$.

\section{Results and Discussion}

\subsection{Experimental Results}

To control the production process on a bench scale, critical points for water and ethanol mixtures were calculated. It was considered that the reactor contained fractional amounts of water and ethanol and that the oil was immobilized inside the seed. Also calculated for each fraction were the critical temperatures and critical pressures, as molar concentrations to be used experimentally. To calculate the points of the mixture, Peng Robinson's equation of state was used. The curves of temperature and critical pressure for a mixture of ethanol and water are shown in Figure 1.

After pressure and temperature values were defined, it was possible to proceed with biodiesel production and then to process the data as proposed in the experimental design.

The product obtained from the reactions of soybean "in natura" and ethanol is shown in Figure 2. As product of each reaction was identified: soybean toasted particles, fatty acid ethyl ester, biodiesel, ethanol and glycerol. After collection the product was found to exist in two phases: liquid oil and black-colored solids. Inside of reactor was verified toasted seed retained, it was in grain format. After each experiment was necessary to remove the toasted seed for put new sample of soybean "in natura" to do a new reaction.

To obtain biodiesel the components of the wort were separated: ultra-centrifugation was carried out to separate the fine solids, and rotoevaporation was carried out to separate the unreacted ester of ethanol. After obtaining biodiesel esters and conducting preliminary evaluations, the viscosity was measured and a reading of 5.4 $\mathrm{mm}^{2} / \mathrm{s}$ was obtained. Figure 3 presents the biodiesel obtained from the reaction.

Statistical analysis was based on the outcome yield $\mathrm{w} / \mathrm{w}$ of the experiments, and the maximum conversion obtained was in Experiment 11, with 94.87\%. Yields calculated and experimental conditions are shown in Table 2 .

The coefficients and the estimated effects with respective statistical indices for the linear model with no interactions are presented in Table 3.

Regarding the granulometry of seed, molar ratio (ethanol:oil) and temperature, a change in the level of -1 to +1 causes an increase in the yield of biodiesel. 


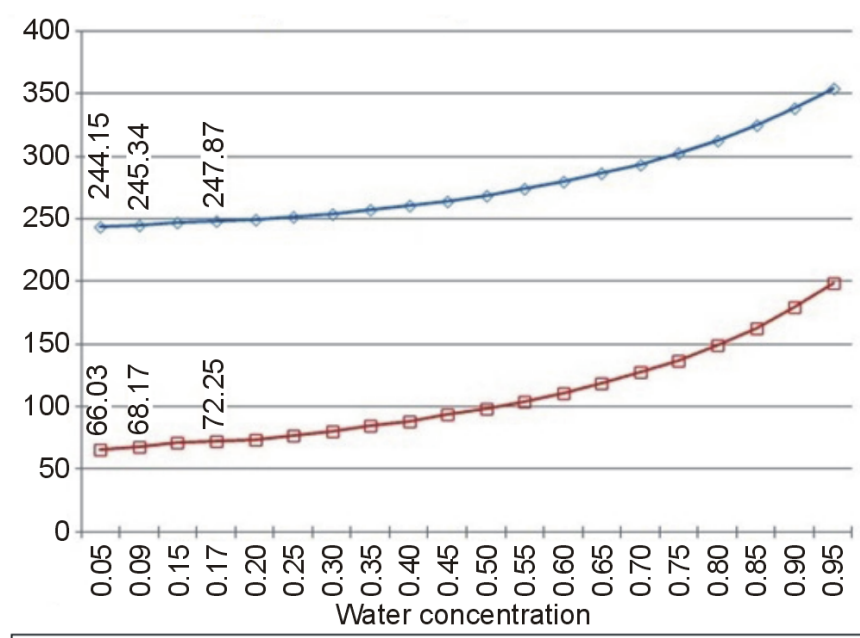

$\rightarrow$ Critical temperature of the mixture $\left({ }^{\circ} \mathrm{C}\right)-$ Critical pressure of the mixture (bar)

Figure 1. Curves of temperature and critical pressure for a mixture of ethanol and water.

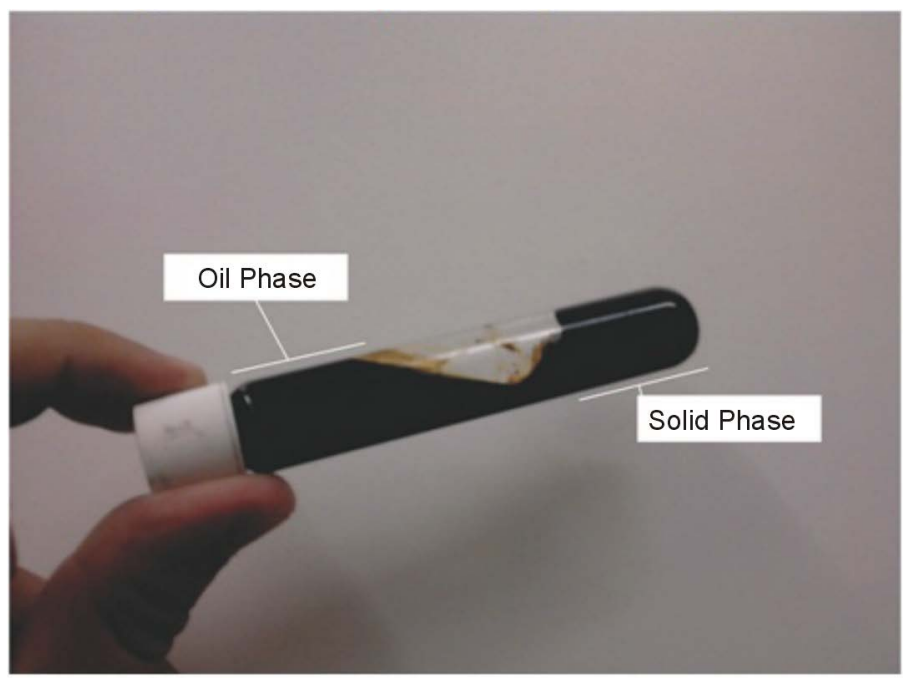

Figure 2. Oil and solid phases occurring before centrifugation.

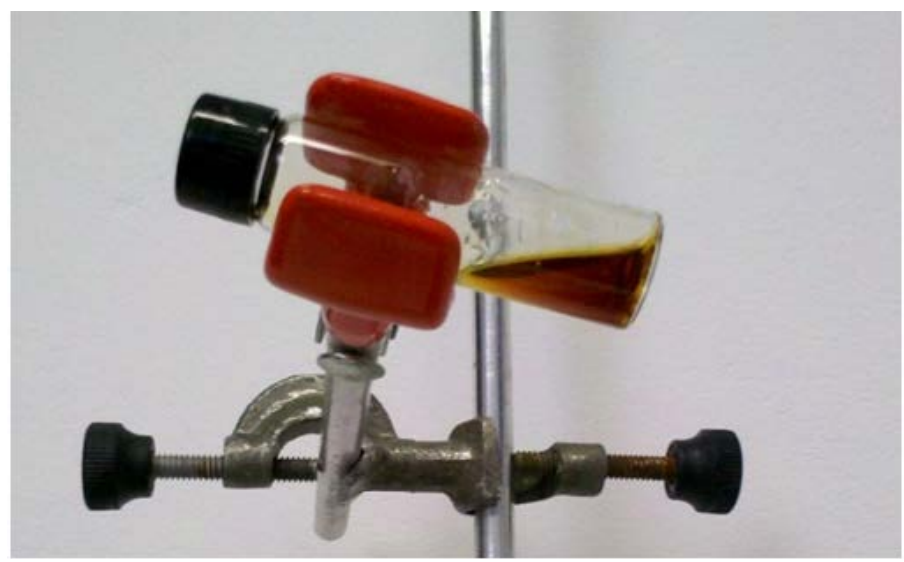

Figure 3. Photography of the ester obtained after evaporation of the ethanol. 
Table 2. Percent yield of the experimental procedures.

\begin{tabular}{|c|c|c|c|c|c|}
\hline Exp & Seed granulometry & $\begin{array}{l}\text { Molar ratio } \\
\text { (ethanol:oil) }\end{array}$ & Temperature & $\begin{array}{l}\text { Water percent of } \\
\text { mixture }\end{array}$ & Yield \% \\
\hline 1 & -1 & -1 & -1 & -1 & 11.14 \\
\hline 2 & +1 & -1 & -1 & +1 & 15.06 \\
\hline 3 & -1 & +1 & -1 & +1 & 2.47 \\
\hline 4 & +1 & +1 & -1 & -1 & 45.13 \\
\hline 5 & -1 & -1 & +1 & +1 & 37.20 \\
\hline 6 & +1 & -1 & +1 & -1 & 9.32 \\
\hline 7 & -1 & +1 & +1 & -1 & 15.96 \\
\hline 8 & +1 & +1 & +1 & +1 & 26.07 \\
\hline 9 & 0 & 0 & 0 & 0 & 87.86 \\
\hline 10 & 0 & 0 & 0 & 0 & 65.51 \\
\hline 11 & 0 & 0 & 0 & 0 & 94.87 \\
\hline
\end{tabular}

Table 3. Estimated effects and coefficients with their statistical indices.

\begin{tabular}{ccccccc}
\hline Factors & Effects & $\begin{array}{c}\text { Standard } \\
\text { Deviation }\end{array}$ & $\mathrm{t}(6)$ & $\mathrm{p}$ & $\begin{array}{c}-95 \% \\
\text { Cnf.L. }\end{array}$ & $\begin{array}{c}+95 \% \\
\text { Cnf.L }\end{array}$ \\
\hline Seed granulometry (1) & 7.203 & 29.32 & 0.246 & 0.814 & -64.50 & 78.95 \\
Molar ratio (ethanol:oil) (2) & 4.228 & 29.32 & 0.144 & 0.890 & -67.50 & 75.98 \\
Temperature (3) & 3.687 & 29.32 & 0.126 & 0.904 & -68.10 & 75.44 \\
$\begin{array}{c}\text { Water percent of mixture } \\
\text { (4) }\end{array}$ & -0.188 & 29.32 & -0.006 & 0.995 & -71.90 & 71.56 \\
Mean & 37.326 & 12.500 & 2.985 & 0.024 & 6.7 & 67.92 \\
\hline
\end{tabular}

The reduction of the water concentration has a negative effect on the yield of fatty acid ethyl esters. It could be verified that there was an effect from varying the concentration of water in the reaction from $5 \%$ to $10 \% \mathrm{w} / \mathrm{w}$, representing a slight increase in the yield. The study was conducted under the following experimental conditions: molar ratio ethanol: $40: 1$ oil pressure of 200 bar and temperatures of $325^{\circ} \mathrm{C}, 300^{\circ} \mathrm{C}$, and $275^{\circ} \mathrm{C}$ with a flow rate of 0.8 to $2.5 \mathrm{~mL} / \mathrm{min}$ [7]. The production of esters with supercritical process is slightly improved in the presence of water with concentrations of $4 \%$ to $20 \% \mathrm{w} / \mathrm{w}$ [10].

For the transesterification process using soybean seed, the seed granulometry was the factor with the highest significance with an effect estimated at 7.203. The experiment considered some variation of temperatures: $245^{\circ} \mathrm{C}, 255^{\circ} \mathrm{C}$ and $265^{\circ} \mathrm{C}$. We sought to keep the fluid in supercritical conditions in order not to degrade the seed structure. From the proposed conditions it could be verified that the seed granulometry was associated with the mass transfer and availability of oil from the seed to the reaction medium. This factor had a higher significance for the yield of ester biodiesel than other factors studied. This condition can be supported by the basic rules of mass transfer, namely that due to the greater surface area of contact between solid and fluid mediums it is easier to transfer the oil from inside the seed to supercritical ethanol medium, where the transesterification reaction occurs.

Statistical analysis indicated that for higher temperatures, higher molar ratios, smaller granulometry and higher water concentrations up to $17 \%$ there is an increased yield of esters in a supercritical transesterification reaction, as shown in Figure 4, Figure 5 and Figure 6. This result has been confirmed by other authors [1] [7]-[10].

\subsection{Analytical Results}

In a second step, a preliminary evaluation was made of the chemical quality of the biodiesel. It was possible to verify the presence of ester palmitate, stearate, oleate, linoleate and linolenate. The composition of the biodiesel produced was between C16 - C18:3 with higher concentrations of oleate (C18:1). This composition is 
considered of good quality. The presence of higher levels of the esters linoleate (C18:2) and linolenate (C18:3) compared to other esters gives favorable oxidation characteristics because the greater the presence of instaurations (double bonds), easier the oxidation of fatty acid ethyl ester [11] [12].

An evaluation of the fatty acid ethyl ester composition produced verified means of $57 \%$ oleate $26 \%$ linoleate and $1 \%$ linolenate. It was verified that the composition of esters varies with the time inside the reactor, possibly because of the tendency for degradation of the most unstable esters [13]. Table 4 presents the results of experiments which verified the better composition. To evaluate a quality of biodiesel was considered the percent of each ester was considered that the high percentage of C18:1 represents high resistance of oxidation being this a indicative of good quality of biodiesel. Experiments 9, 10 and 11 showed a better quality of biodiesel. It was observed that identical experimental conditions had different ester concentrations in the final composition.

From the process of production of biodiesel using soybean seed "in natura" the possibility of reuse of toasted soybean seed was identified. Was identified that it is possible to use the seeds as coal. To confirm the heat potential of the coal an experimental analysis was carried out (TGA-DTA).

In the thermogravimetric analysis, the biomass soybean seed was subjected to burning and proved to be stable during degradation. Sparks were not ejected, and it was verified that the seeds burned uniformly. The value of $2203.17 \mathrm{kcal} / \mathrm{kg}$ to calorific power was obtained.

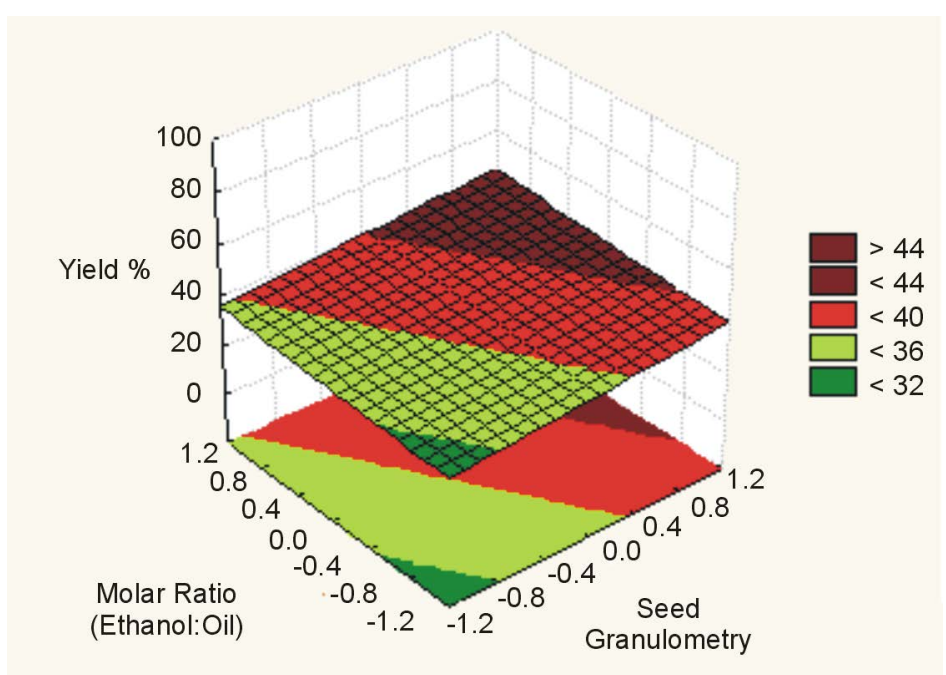

Figure 4. Yield (\%) for molar ratio (ethanol:oil) vs. seed granulometry.

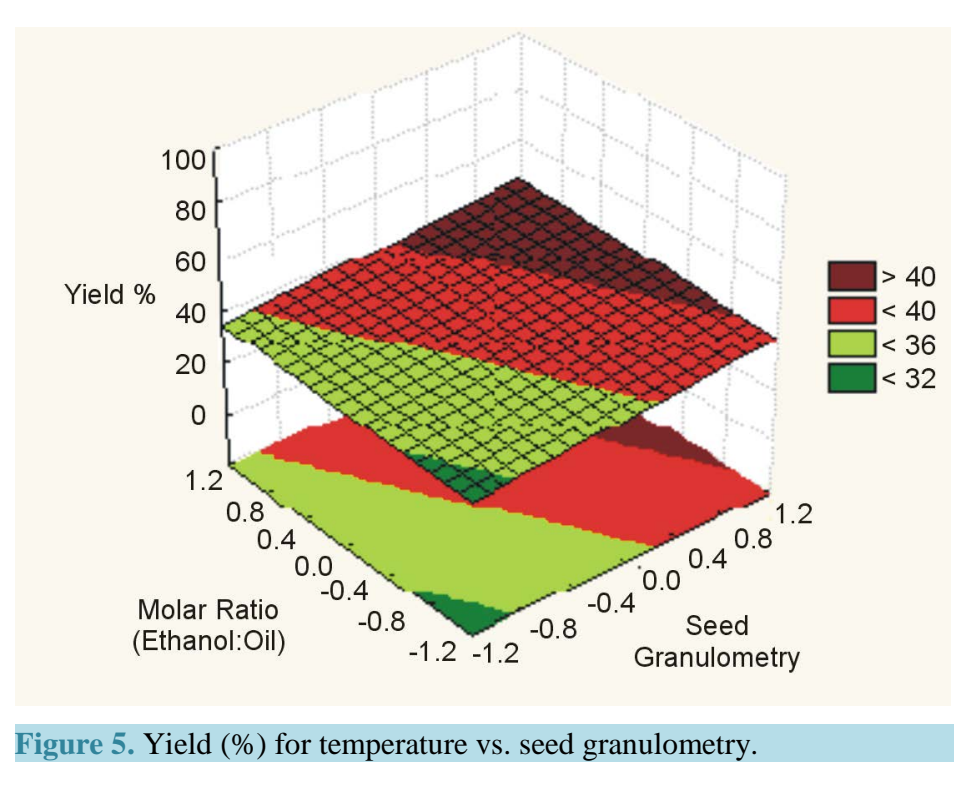




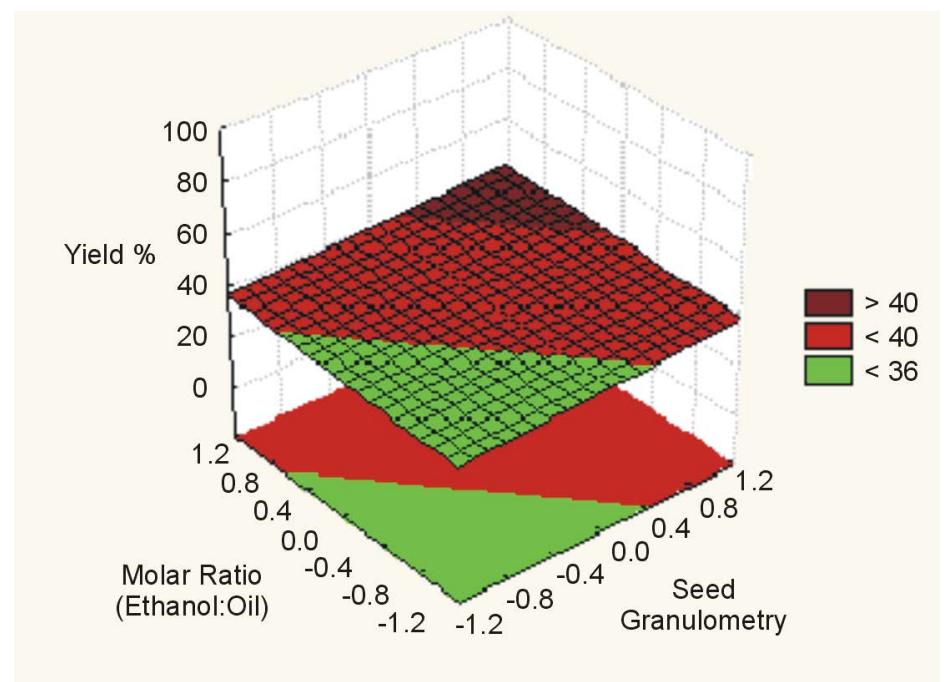

Figure 6. Yield (\%) for temperature vs. molar ratio (ethanol:oil).

Table 4. Composition of ester biodiesel for experiments with better composition.

\begin{tabular}{cccccccc}
\hline No. of Carbon & $\begin{array}{c}\text { Fatty acid ethyl } \\
\text { ester }\end{array}$ & Exp 1 & Exp 7 & Exp 8 & Exp 9 & Exp 10 & Exp 11 \\
\hline C16:0 & Palmitate & 11.68 & 7.85 & 7.94 & 7.54 & 7.86 & 7.38 \\
C18:0 & Stearate & 6.14 & 8.31 & 5.06 & 2.97 & 1.5 & 8.5 \\
C18:1 & Oleate & 58.40 & 46.6 & 47.1 & 82.67 & 85.19 & 77.2 \\
C18:2 & Linoleate & 23.78 & 33.5 & 39.9 & 6.82 & 5.45 & 6.92 \\
C18:3 & Linolenate & 0 & 3.74 & 0 & 0 & 0 & 0 \\
& Yield (\%) & 11.14 & 15.96 & 26.07 & 87.86 & 65.51 & 94.87 \\
\hline
\end{tabular}

The results indicate that coal soybean seed can be considered an energetic coal with good properties. In comparison with the coals used in Brazil it can be verified that the soybean seed toast has a calorific value of $2203.17 \mathrm{kcal} / \mathrm{kg}$, higher than the sugarcane bagasse 50\% (1800 kcal/kg) and similar to palm fiber $48 \%$ (2000.00 $\mathrm{kcal} / \mathrm{kg}$ ) and $40 \%$ wood (2400.00 kcal/kg).

\section{Conclusion}

From the reaction process for the soybean seed and supercritical ethanol it was possible to obtain fatty acid ethyl ester with good composition in regard to stability of oxidation. The experiments showed that when used a temperature of $255^{\circ} \mathrm{C}$, molar ratio 20:1, granulometry condition (0) broken seed and water concentration of $11 \%$, an increased of the yield of esters was obtained. The numerical results of statistical analysis, effects and coefficients, suggested that by employing a combination of smaller seed granulomety, molar ratio 30:1, temperature of $265^{\circ} \mathrm{C}$, and water concentrations of $17 \%$, we can improve the yield of esters. These considerations are in accordance with the results of other authors [1] [7]-[10].

\section{Acknowledgements}

This work was supported by CNPq, National Council for Scientific and Technological Development, Brazil.

\section{References}

[1] Demirbas, A. (2003) Biodiesel Fuels from Vegetable Oils via Catalytic and Non-Catalytic Supercritical Alcohol Transesterifications and Other Methods: A Survey. Energy Conversion and Management, 44, 93-109.

[2] Bala, B.K. (2005) Studies on Biodiesels from Transformation of Vegetable Oils for Diesel Engines. Energy Education Science Technology, 15, 1-43. 
[3] Kusdiana, D. and Saka, S. (2004) Effects of Water on Biodiesel Fuel Production by Supercritical Methanol Treatment. Bioresource Technology, 91, 289-295. http://dx.doi.org/10.1016/S0960-8524(03)00201-3

[4] Demirbas, A. (2006) Biodiesel Production via Non-Catalytic SCF Method and Biodiesel Fuel Characteristics. Energy Conversion and Management, 47, 2271-2282. http://dx.doi.org/10.1016/j.enconman.2005.11.019

[5] Pinto, A.C., Guarieiro, L.L.N., Rezende, M.J.C., Ribeiro, N.M., Torres, E.A., Lopes, W.A., Pereira, P.A.P. and Andrade, J.B. (2005) Biodiesel: An Overview. Journal of the Brazilian Chemical Society, 16, 1313-1330. http://dx.doi.org/10.1590/S0103-50532005000800003

[6] Silva, C. (2007) Produção de Ésteres Etílicos por Transesterificação não catalítica de Óleo de Soja. Dissertação de Mestrado, Departamento de Ciências Agrárias, URI Campus Erechim, 132 p.

[7] Vieitez, I., Silva, C., Borges, G.R., Corazza, F.C., Oliveira, J.V., Grompone, M.A. and Jachmanián, I. (2008) Continuous Production of Soybean Biodiesel in Supercritical Ethanol-Water Mixtures. Energy \& Fuels, 22, 2805-2809. http://dx.doi.org/10.1021/ef800175e

[8] Kusdiana, D. and Saka, S. (2001) Biodiesel Fuel from Rapeseed Oil as Prepared in Supercritical Methanol. Fuel, 80, 225-230. http://dx.doi.org/10.1016/S0016-2361(00)00140-X

[9] Anitescu, G. and Tavlarides, L.L. (2009) Integrated Multistage Supercritical Technology to Produce High Quality Vegetable Oils and Biofuels. Syracuse University, Intl. Patent Appl. WO 2008101200 A2 20080821, Sept.18.

[10] Tan, K.T., Lee, K.T., Mohamed, A.R. and Bhatia, S. (2009) Palm Oil: Addressing Issues and towards Sustainable Development. Renewable \& Sustainable Energy Reviews, 13, 420-427. http://dx.doi.org/10.1016/j.rser.2007.10.001

[11] Knothe, G., Gerpen, J.V., Krahl, J. and Ramos, L.P. (2006) Manual Do Biodiesel. Edgard Blucher, São Paulo, 340 p.

[12] Neff, W.E., Selke, E., Mounts, T.L., Rinsch, W., Frankel, E.N. and Zeitoun, M.A.M. (1992) Effect of Triacylglycerol Composition and Structures on Oxidative Stability of Oils from Selected Soybean Germplasm. Journal of the American Oil Chemists' Society, 69, 111-118.

[13] Vieitez, I., Silva, C., Alckmin, I., Castilhos, F., Oliveira, J.V., Grompone, M.A. and Jachmanián, I. (2011) Stability of Ethyl Esters from Soybean Oil Exposed to High Temperatures in Supercritical Ethanol. Journal of Supercritical Fluids, 56, 265-270. http://dx.doi.org/10.1016/j.supflu.2010.10.033 
Scientific Research Publishing (SCIRP) is one of the largest Open Access journal publishers. It is currently publishing more than 200 open access, online, peer-reviewed journals covering a wide range of academic disciplines. SCIRP serves the worldwide academic communities and contributes to the progress and application of science with its publication.

Other selected journals from SCIRP are listed as below. Submit your manuscript to us via either submit@scirp.org or Online Submission Portal.
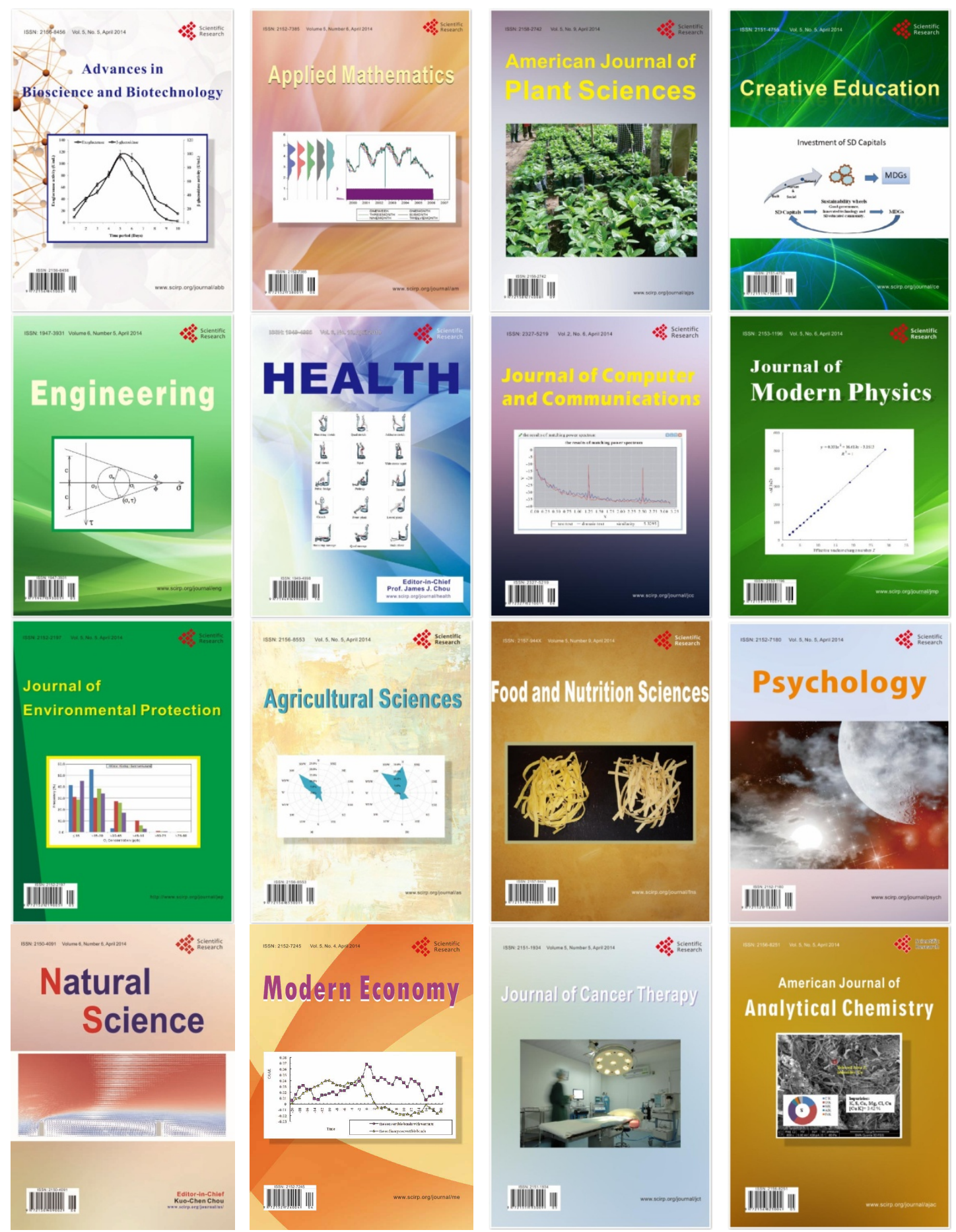